\title{
Effect of Combined Beam Slab Interactive Resisting Mechanism for Progressive Collapse
}

\author{
Gokul P, Vandhiyan R, Vijay TJ
}

\begin{abstract}
In reinforced concrete structures slab, beam and column plays an important role in load transfer mechanism. When a column fails due to earthquake or attack, progressive collapse may occur. There is a need to study and understand the performance of the $R C$ framed structure under progressive collapse to design a better structure. This study investigates the effect of combined Beam-Slab interactive resisting mechanism against progressive collapse using finite element software. Linear static analysis was used to study the progressive collapse of the $R C$ framed structure. The models of symmetrical regular building with bare frame, frame with slab and frame slab with infill were studied. The parameters like load carrying capacity, energy dissipation factor and stiffness degradation were analysed. The analysis results showed that frame slab with infill showed better resistance during progressive collapse.
\end{abstract}

Keywords : Progressive Collapse, column removal, Slab-beam assembly, energy dissipation, stiffness, Abaqus.

\section{INTRODUCTION}

In the past few years, number of terrorist attacks has increased across the globe. There is a need to improve the performance of the structures to make them safer and less vulnerable to progressive collapse. Progressive collapse is defined as "a situation where local failure of a primary structural component leads to the collapse of adjoining members, which, in turn, leads to additional collapse [1]. Hence the total damage is disproportionate to the original cause".

Loss of a structural component could be due to impact of a car, fire, earth quake, flood, explosion or an airplane crash etc. The key factor in designing structures is their ability to prevent total collapse after the loss of load-carrying component.

During progressive collapse the structure goes through the following mechanisms to resist collapse contributions from

Revised Manuscript Received on April 27, 2020.

* Correspondence Author

Gokul P*, PG II-year Student, Department of Civil Engineering, PSNA College of Engineering and Technology, Dindigul, India. Email: pgokulsanthosh143@gmail.com

Vandhiyan R, Assistant Professor, Department of Civil Engineering, PSNA College of Engineering and Technology, Dindigul, India. Email: vandhianr@gmail.com

Vijay T J, Assistant Professor, Department of Civil Engineering, PSNA College of Engineering and Technology, Dindigul, India. Email: tjvijay2@gmail.com

(C) The Authors. Published by Blue Eyes Intelligence Engineering and Sciences Publication (BEIESP). This is an open access article under the CC BY-NC-ND license (http://creativecommons.org/licenses/by-nc-nd/4.0/) infill walls and slabs, flexural action of beams, vierendeel action, compressive arch action of the frame and catenary action [2], [3] as a column is removed the beams resting on the column go into flexural action trying to resist deflection. As the load increase beams elongate leading to large deformation, yielding and cracks, this leads to lateral force on the columns supporting the beams to resist failure this behavior is called compressive arch action [3].

As deflection further increases the beams further deflects forming a catenary like shape to resist failure and behaviors like a tension member. Catenary action will happened only under large displacements and deformations of beams and it will also occurs when the beams no longer act as structural elements subjected mainly to bending, and the vertical loads are instead transferred to the adjacent vertical structural elements [3]. During this failure mechanisms, the shear force increases in the beams, leading to formation of hinges in the critical locations mostly near the columns. This mechanism is called vierendeel action [4]. In previous works, progressive collapse was studied by the sudden loss of center column in a 3D frame. In few literatures improvement in collapse resistance due to the contribution of slab was also studied [2]. In this work, the contribution of brick-infill was investigated in addition to the influence of slab in beam column assembly. The effect of sudden loss of one corner column was explored. Parameters like load displacement relationship, energy dissipation and stiffness degradation were used to compared the performance of various models.

\section{FINITE ELEMENT MODELING AND ANALYSIS}

ABAQUS software was used to analyze the various models involved in this work [4], [11]. A 3D RC frame with two bay and two stories was created with open base as shown in Fig.1 and Fig. 2. The cross section of the beams and columns were $230 \mathrm{~mm}$ x $380 \mathrm{~mm}$. The 8 nodal hexahedral brick element with reduced hour glass control was used to model the concrete element with the constant mess size of $10 \mathrm{~mm}$. The 2 nodded truss elements were used to represent steel reinforcements with the mesh size of $15 \mathrm{~mm}$. The embedded contact algorithm available in ABAQUS was used to create the bond between steel and concrete. The material properties of concrete and steel are given in Table-I. Concrete damaged plasticity approach was used to study the concrete failure and steel failure behavior was represented using the elastic approach [3], [5].

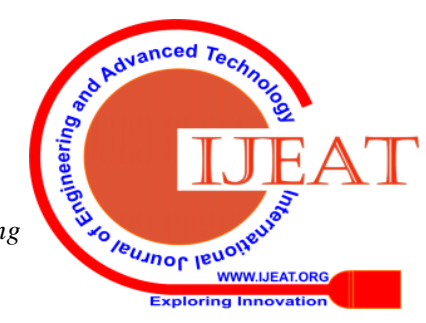


Table- I: Properties of Materials

\begin{tabular}{|l|l|l|l|}
\hline \multirow{2}{*}{ Property } & \multicolumn{3}{|c|}{ Material } \\
\cline { 2 - 4 } & \multicolumn{1}{|c|}{ Concrete } & \multicolumn{1}{|c|}{ Steel } & \multicolumn{1}{c|}{ Brick } \\
\hline Density $\left(\mathrm{kN} / \mathrm{m}^{3}\right)$ & 24.00 & 78.50 & 21.00 \\
\hline $\begin{array}{l}\text { Young's Modulus } \\
\left(\mathrm{N} / \mathrm{mm}^{2}\right)\end{array}$ & 25000 & 21000 & 20000 \\
\hline Poisson's ratio & 0.18 & 0.3 & 0.26 \\
\hline
\end{tabular}

Three different models were created to study the effect of slab and brick infill in resisting progressive collapse. Model-1 an ordinary bare frame with only beam-column assembly (Fig. 3). The loads from slab and brick infill were applied as pressure loads on beams. The loading was increased until the frame reached failure. The design of bare frame was carried out as per IS standards using STAAD.Pro software. The reinforcement details provided in the structural element are listed in Table-II. Fixed support conditions were applied at the base of all columns of the frame.

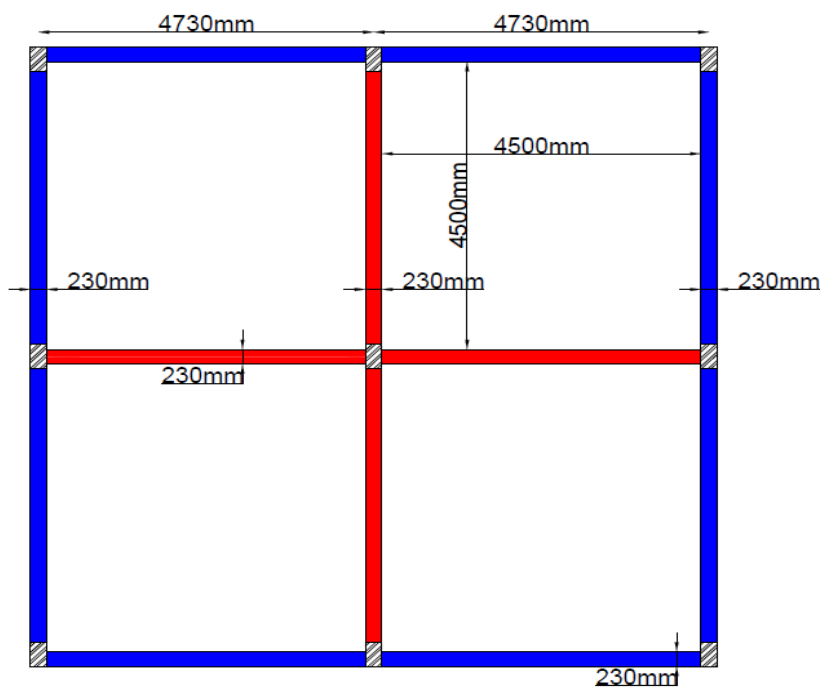

Fig. 1.Plan of the RC Frame

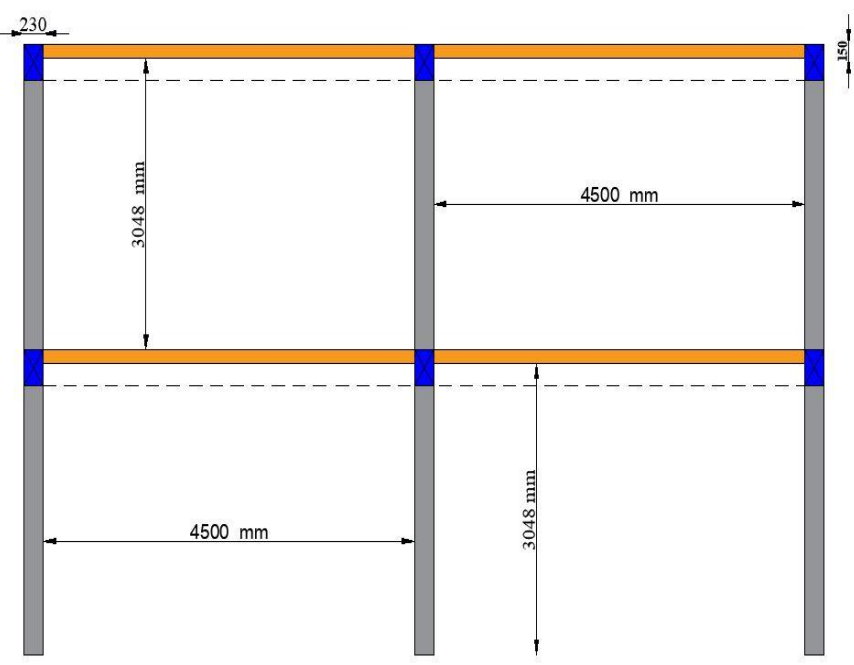

Fig. 2.Elevation of the RC Frame

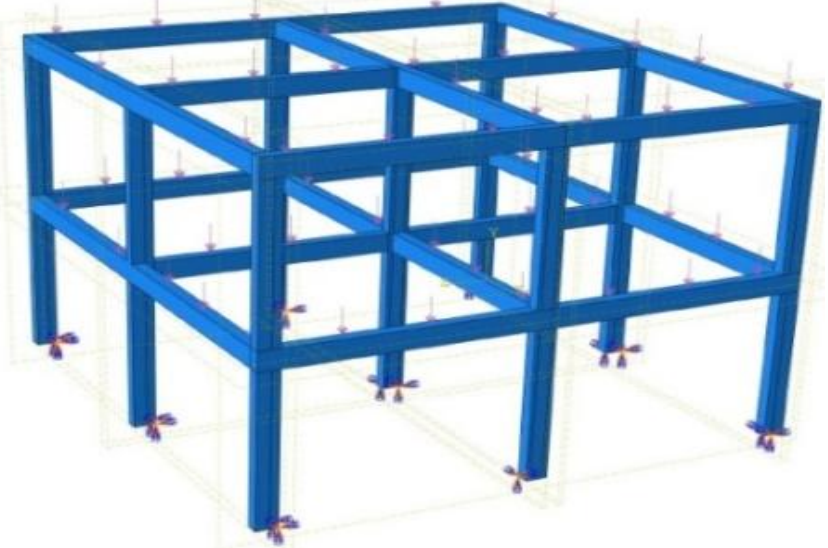

Fig. 3.Assembly and Support condition of Model-1

In Model-2 frame with only slab assembly was made (Fig.4). The slabs were of $150 \mathrm{~mm}$ thickness. The load from brick infill was applied as pressure loads on beams. Beams and slabs were connected using surface to surface contact to enable truthful interface. The live load in slab and dead load of beam was applied as pressure on the slabs and beams. So that the load values was similar the Model-1

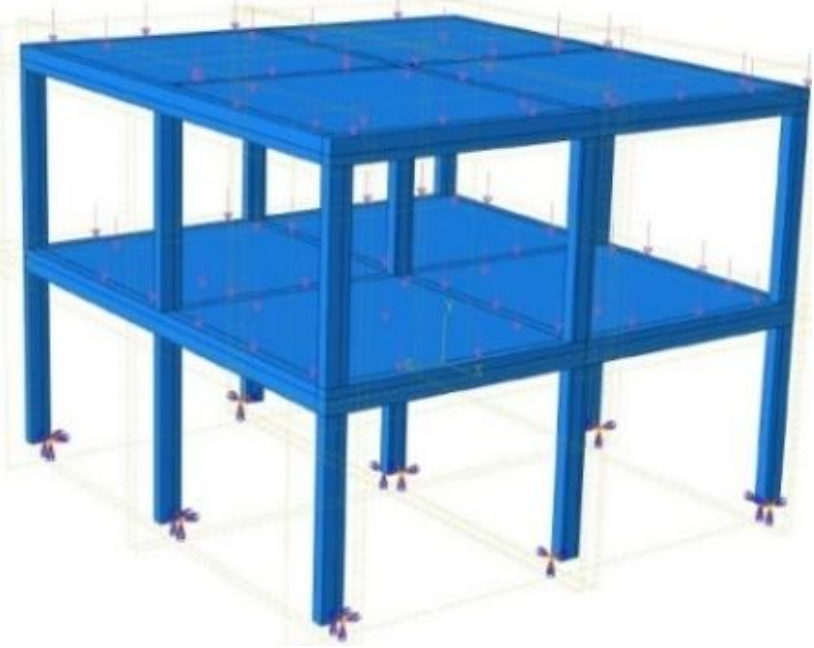

Fig. 4.Assembly and Support condition of Model-2

In Model-3 frame was modeled with concrete slab and brick infill (figure 5). Brick infill was provided in all the beams in the second story [6] and surface to surface contact was created for proper interface. The live load on the slab was applied as pressure and the equal load values were applied on all the models.

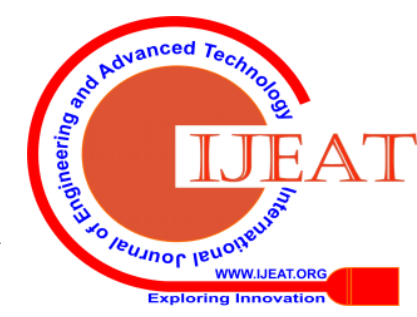




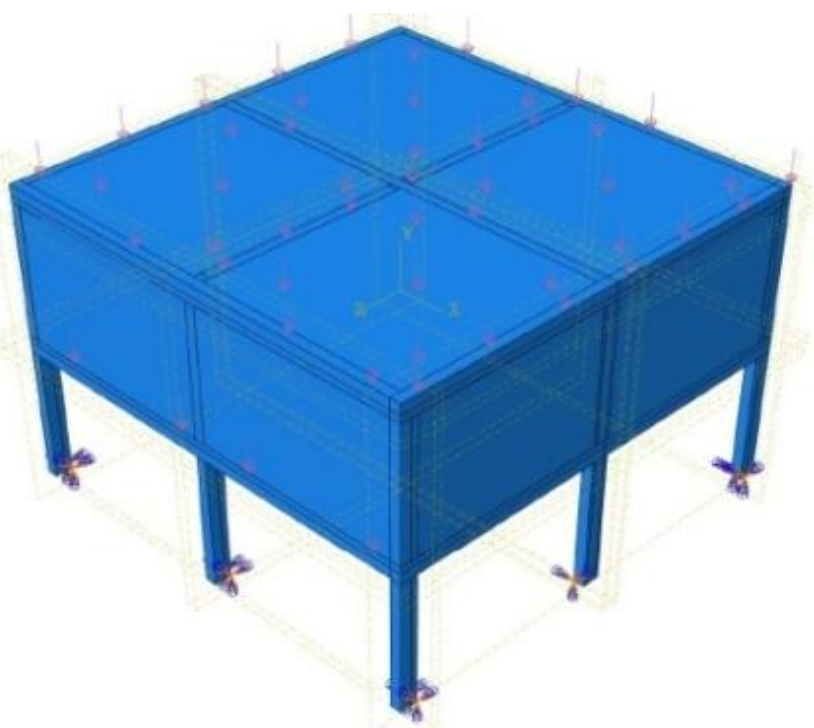

Fig. 5.Assembly and Support condition of Model-3 Table- II: Reinforcement Details

\begin{tabular}{|c|c|c|c|c|c|}
\hline Specimen & Size & \multicolumn{3}{|c|}{ Reinforcement } & Stirrups \\
\hline \multirow{2}{*}{$\begin{array}{l}\text { Outer } \\
\text { beams }\end{array}$} & \multirow{2}{*}{$230 \times 380 \mathrm{~mm}$} & top & \multicolumn{2}{|c|}{$4 \# 10 \mathrm{~mm} \phi$} & \multirow{2}{*}{$\begin{array}{c}8 \mathrm{~mm} \phi \text { at } \\
130 \mathrm{~mm} \mathrm{c/c}\end{array}$} \\
\hline & & bottom & \multicolumn{2}{|c|}{$4 \# 10 \mathrm{~mm} \phi$} & \\
\hline \multirow{2}{*}{$\begin{array}{c}\text { Inner c/c } \\
\text { beams }\end{array}$} & \multirow{2}{*}{$230 \times 380 \mathrm{~mm}$} & top & \multicolumn{2}{|c|}{$4 \# 12 \mathrm{~mm} \phi$} & \multirow{2}{*}{$\begin{array}{c}8 \mathrm{~mm} \phi \text { at } \\
250 \mathrm{~mm} \mathrm{c} / \mathrm{c}\end{array}$} \\
\hline & & bottom & \multicolumn{2}{|c|}{ 3\#12mm $\phi$} & \\
\hline Column & $230 \times 380 \mathrm{~mm}$ & \multicolumn{3}{|c|}{$4 \# 12 \mathrm{~mm} \phi$} & $\begin{array}{c}8 \mathrm{~mm} \phi \text { at } \\
200 \mathrm{~mm} \mathrm{c} / \mathrm{c}\end{array}$ \\
\hline \multirow[b]{2}{*}{ Slab } & \multirow{2}{*}{$\begin{array}{c}4500 \times 4500 \mathrm{~mm} \\
150 \mathrm{~mm} \mathrm{tk}\end{array}$} & \multicolumn{2}{|c|}{ Main Rod } & \multicolumn{2}{|c|}{ 10mmф@200mm c/c } \\
\hline & & \multicolumn{2}{|c|}{$\begin{array}{c}\text { Distribution } \\
\text { Rod }\end{array}$} & \multicolumn{2}{|c|}{ 8mmф@ 230mm c/c } \\
\hline
\end{tabular}

The Static general solver was used for the analysis [7]. The Fig. 6, Fig. 7 and Fig. 8 shows the stress distribution in the Model-1, Model-2 and Model-3 respectively. Further one column at the corner of the frame was removed and the behavior of the frame was analyzed [4]. The beam attached adjacent to the removal column was selected for the study. The various results from the mid span node of the chosen beam. The Fig. 9, Fig. 10 and Fig. 11 shows the stress distribution after corner column removal in the Model-1, Model-2 and Model-3 respectively.

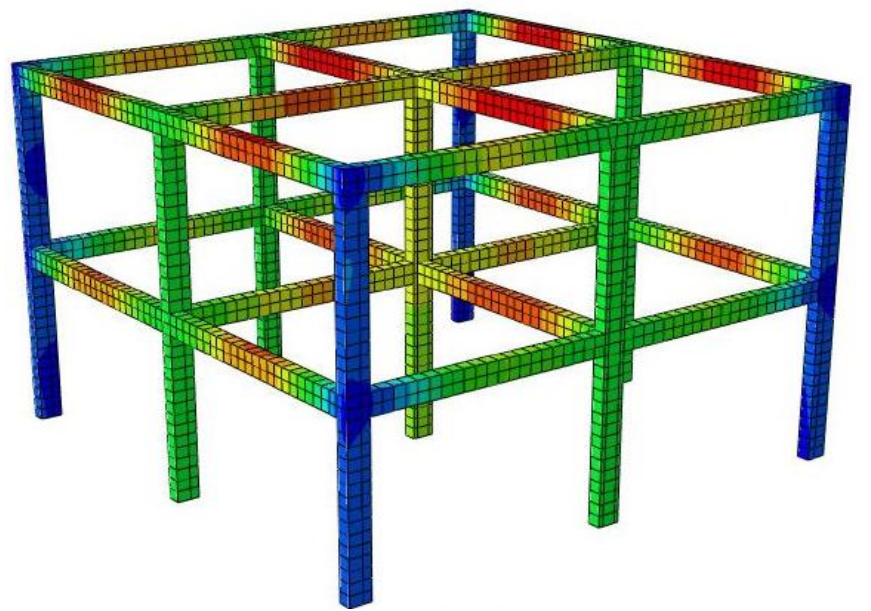

Fig. 6.Stress distribution of Model-1

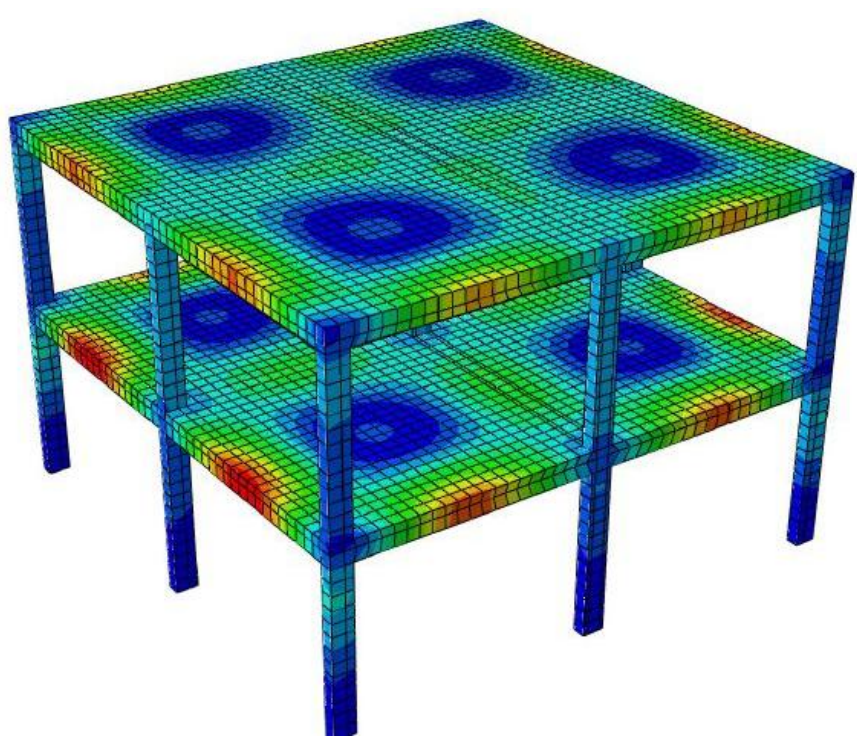

Fig. 7.Stress distribution of Model-2

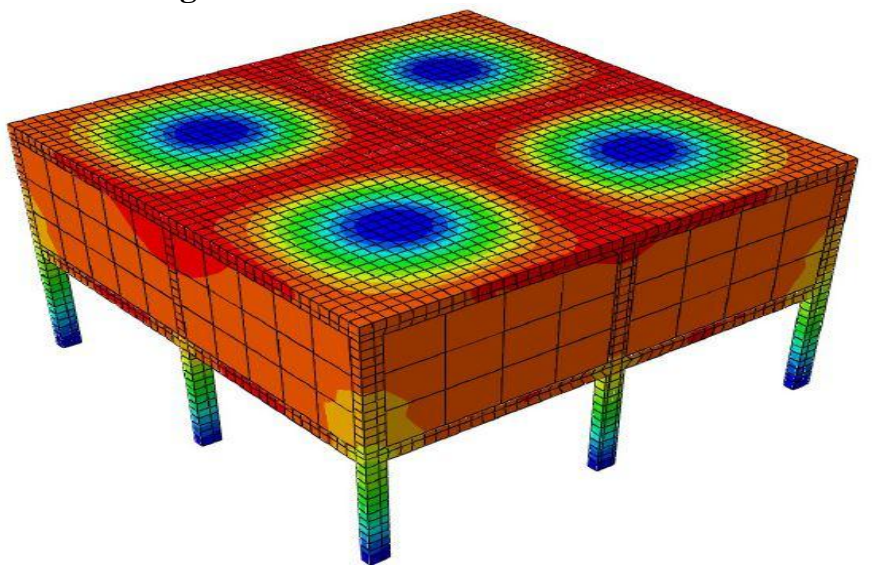

Fig. 8.Stress distribution of Model-3

\section{RESULT AND DISCUSSION}

Load displacement graph (Fig. 12) shows the Model-1 has a maximum deflection of $4.73 \mathrm{~mm}$ at an average load capacity of $56 \mathrm{kN}$. Model-2 and Model-3 had a deflection of $3.40 \mathrm{~mm}$ and $2.93 \mathrm{~mm}$ with an average load capacity of $66 \mathrm{kN}$ and $84 \mathrm{kN}$ respectively. The Model-2 and Model-3 had increased deflection resistance of $28.11 \%$ and $38.05 \%$ respectively compared to Model-1.

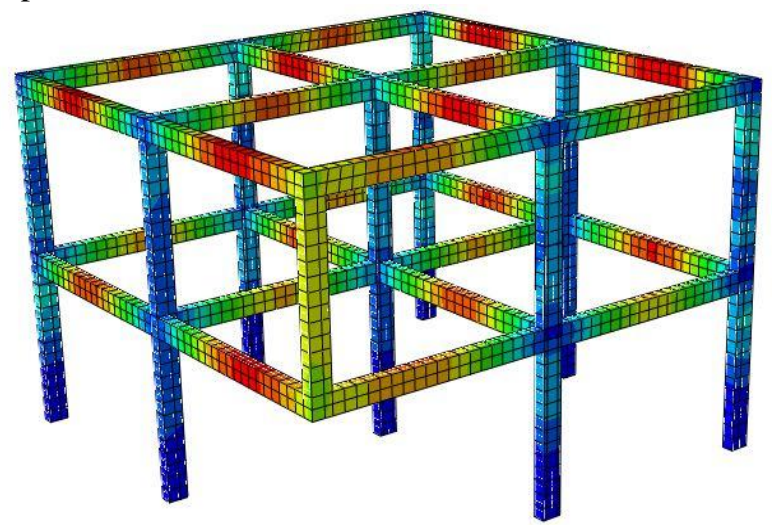

Fig. 9. Stress distribution of Model-1 after column loss

Published By:

Blue Eyes Intelligence Engineering \& Sciences Publication

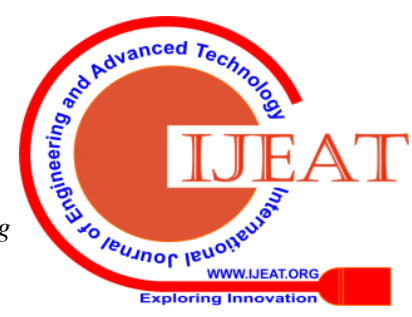




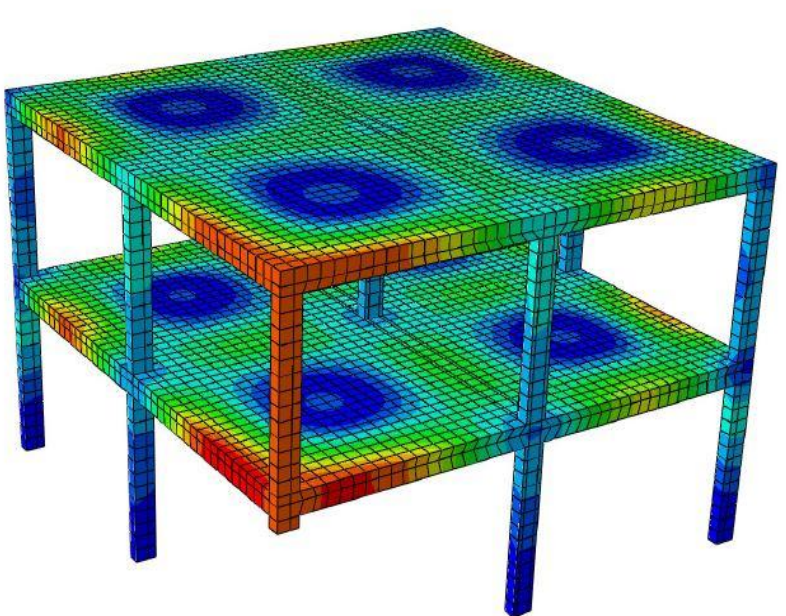

Fig. 10. Stress distribution of Model-1 after column loss

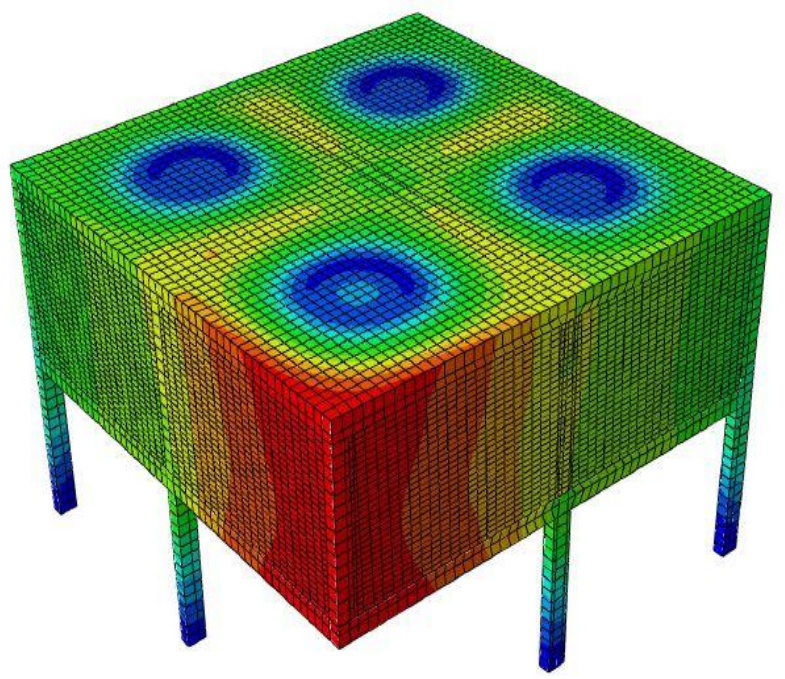

Fig. 11. Stress distribution of Model-1 after column loss Similarly when a corner column was removed from the model, progressive collapse will occur. When the corner column was removed, load displacement graph (Fig. 13), showed Model-1 has a maximum deflection of $32.56 \mathrm{~mm}$ with an average load capacity of $92 \mathrm{kN}$. Model-2 and Model-3 had a deflection of $14.6 \mathrm{~mm}$ and $8.01 \mathrm{~mm}$ with an average load capacity of $221.67 \mathrm{kN}$ and $265.36 \mathrm{kN}$ respectively. The Model-2 and Model-3 had increased deflection resistance of $55.16 \%$ and 75.39\% respectively compared to Model-1.

$\mathrm{RC}$ frame with slab and brick infill enhanced the strength of the specimens and also provided better displacement resistance due to diaphragm effect. Based on the above data, we can conclude that frame slab with brick infill simultaneously was behaving better to resist collapse than Model-1 and Model-2 [8], [10].

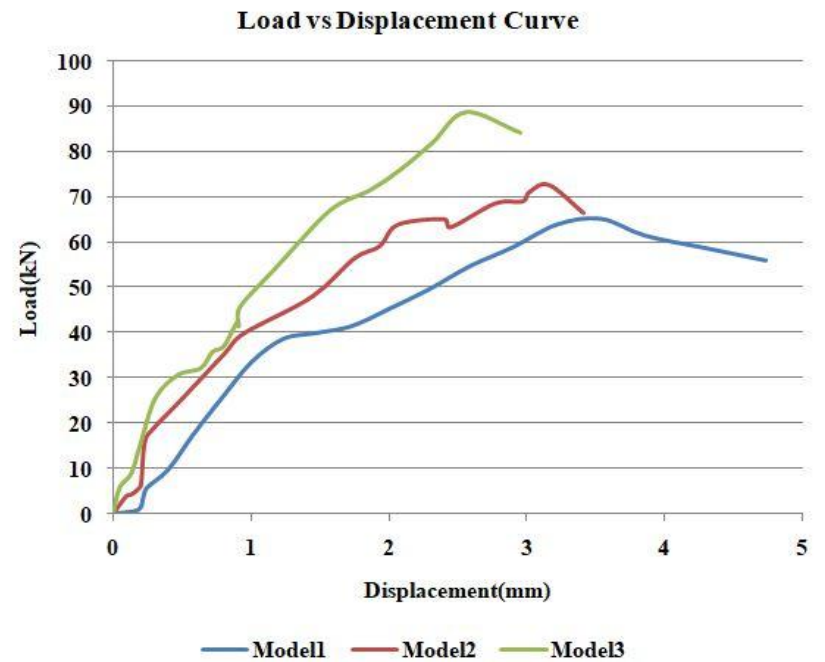

Fig. 12. Load vs. Displacement curve with no column removal

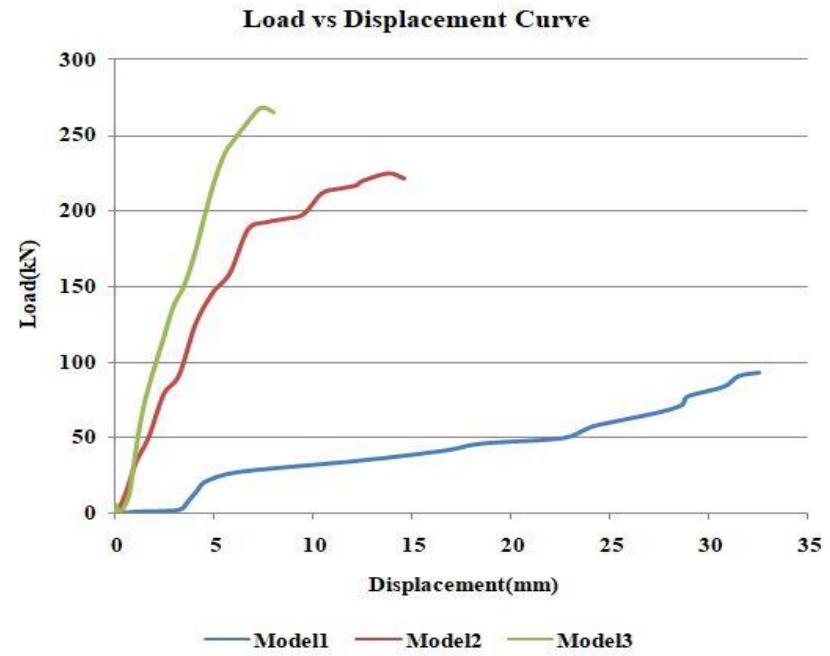

Fig. 13. Load vs. Displacement curve with column loss

Energy dissipation graph (Fig. 14 \& Fig. 15) shows the energy dissipation for the Model-1 was higher than Model-2 and Model-3. This implies that the Model-1 reaches failure with maximum deflection for the given loading condition. But in Model-2 and Model-3 the energy capacity has not reached the ultimate and hence it can accommodate more load. RC frame with slab and brick infill enhanced the strength of the specimens and also provided alternate load path for load redistribution. Hence Model-2 and Model-3 serves a reasonable energy dissipation mechanism and can reduce damage, making the structures better collapse-resistant. The energy dissipation graph shows that, the energy dissipation for the Model-1 was higher than Model-2 and Model-3 after the sudden loss of a corner column [10].

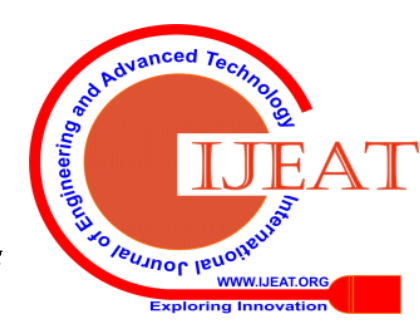




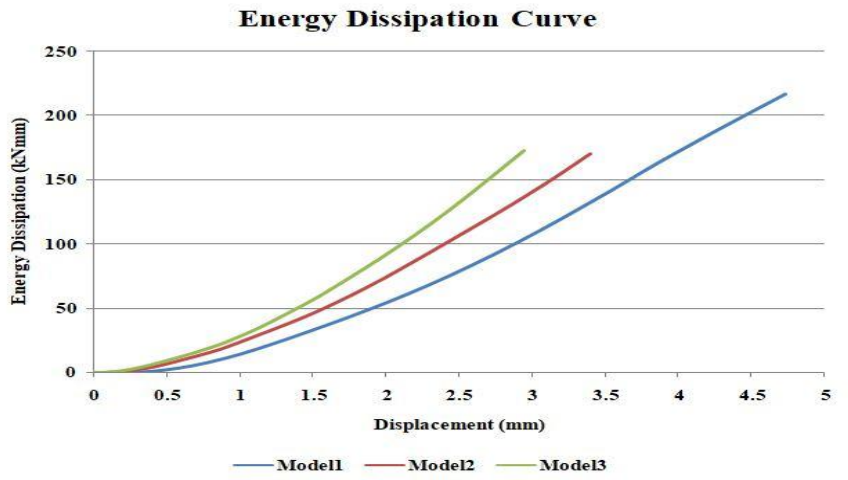

Fig. 14.Energy dissipation curve with No column removal.

Energy Dissipation Curve

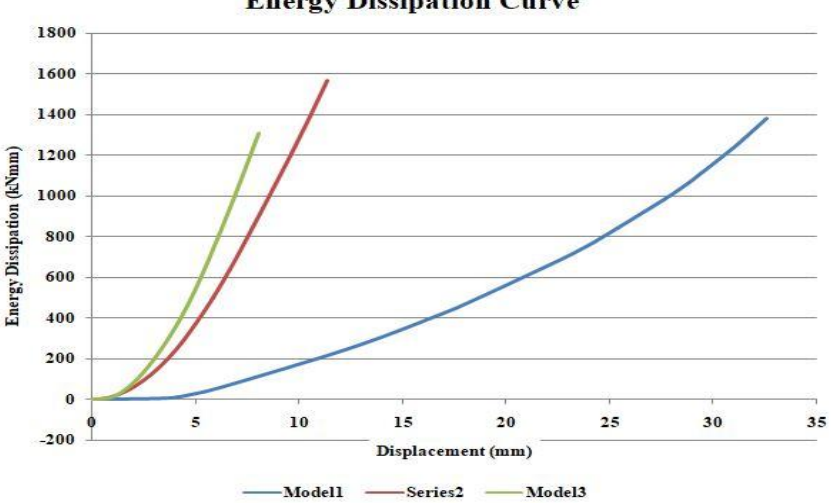

Fig. 15. Energy dissipation curve after column loss.

Stiffness (Fig. 16 \& Fig. 17) of models with slab and brick-infill was high. Stiffness degradation curve shows that the behaviour of RC frame with Slab and infill was performing better than bare frame. It was noticed the stiffness degradation of Model-1 was relatively horizontal compared to other two models. This must be due the additional resistance provided by the infill and slab. Stiffness degradation of Model-2 and Model-3 was following a liner path, this shows a better energy absorption [9], [10]. The enhanced stiffness behavior of Model-2 and Model-3 is due to the resistance offered by the diaphragm effect of the models.

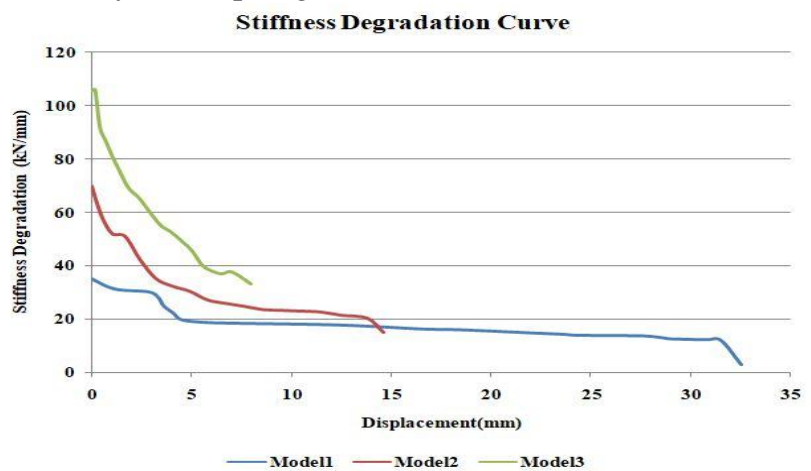

Fig. 16. Stiffness degradation after column loss.

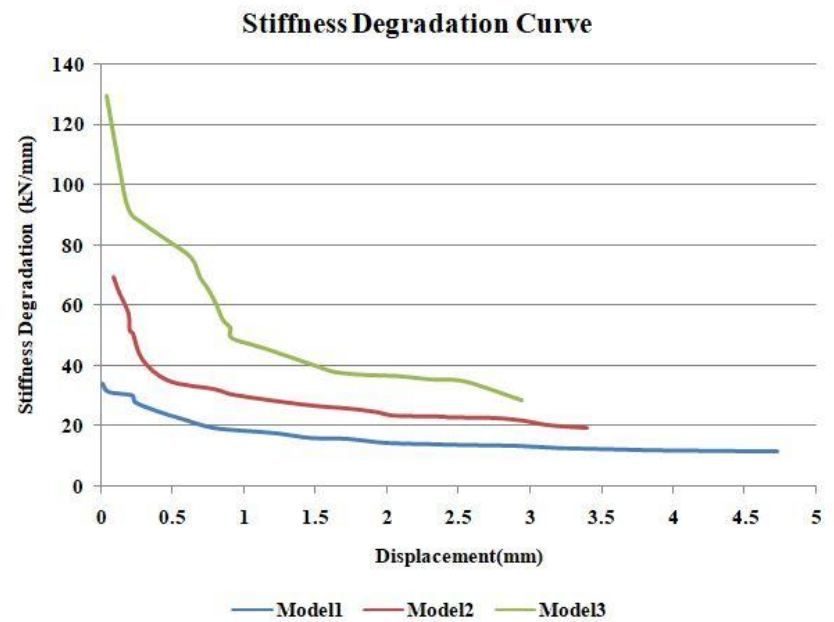

Fig. 17. Stiffness degradation with No column removal

\section{CONCLUSION}

The effect of slab and brick-infill in the behavior of 3D frame was investigated in this work. Load-displacement relationship, energy dissipation and stiffness degradation were used to compare the performance of the different frames.

Displacement of the bare frame was high when compared to the frames with slab and infill. The energy dispersion of frame with slab and brick-infill was better due energy absorption and distribution by the added diaphragm elements.

The stiffness degradation showed an enhanced behavior when slab and brick-infill was present because of its ability to resist deformation and delay the displacement.

The frame with slab was showing a better performance compared to the bare frame. The frame with slab and brick-infill was showing a superior performance. So considering the effect of slab and brick-infill during the design of structures to resist progressive collapse will make the design economical as well as safe.

\section{REFERENCES}

1. GSA (General Service Administration-US) Progressive collapse analysis and design guideline for new federal office buildings and major modernisation projects. June 2003, pp. 119

2. M. Botez, L. Bredean, A.M. Ioani,(2016), 'Improving the accuracy of progressive collapse risk assessment: efficiency and contribution of supplementary progressive collapse resisting mechanisms', Comput. Structures. pp. 54-65

3. Bredan L.A, Boltez M.D. (2018), 'The influence of beams design and the slab effect on the progressive collapse resisting mechanisms development for RC Framed structures', Engineering Failure Analysis Journal, Vol. 91, pp. 527-542.

4. Kai, Q. and Bing, L.,(2012), 'Slab Effects on response of reinforced concrete substructures, after loss of corner column', ACI Structural Journal, Vol. 109

5. Nima Usefi, Foad Mohajeri Nav (12-2016) 'Finite element analysis of RC elements in progressive collapse scenario'.

6. Tsai, M. H. and Huang, T. C. (2010), 'Effect of Interior Brick-Infill Partitions on the Progressive Collapse Potential of a RC Building: Linear Static Analysis Results', International Journal of Engineering and Applied Sciences, 2010.

7. Osama A.Mohamed (2009), 'Assessment of progressive collapse potential in corner floor panels of reinforced concrete buildings', Engineering structures, 31, pp. 749-757.

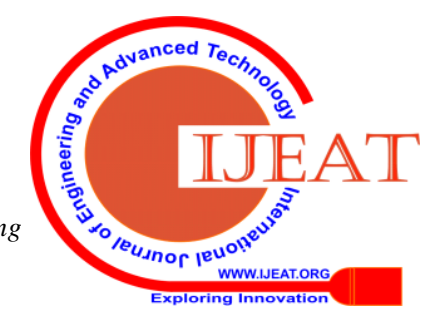


8. Kai Qian, M Bing Li and Jia-Xing M. (2014), 'Load-Carrying Mechanism to Resist Progressive Collapse of RC Buildings', ASCE J. Struct Eng. pp04014107-(1-14)

9. Meng-Hao Tsai, Tsuei-Chiang Huang (2011), 'Progressive Collapse Analysis of an RC Building with Exterior Non-Structural Walls', Procedia Engineering, Vol. 14, pp. 377-384

10. Sidi Shan, Shuang Li, Shiyu Xu, Lili Xie ,'Experimental study on the progressive collapse performance of RC frames with infill walls', Engineering structures 111(2016), pp. 88-92.

11. Tharani K, Mahendran N, Vijay T J, 'Experimental investigation of Geogrid reinforced concrete slab', International Journal of Engineering and Advanced Technology (IJEAT),Vol. 8, Feb 2019, pp.158-163

\section{AUTHORS PROFILE}

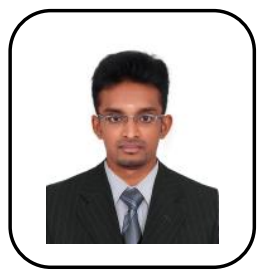

Mr.P.Gokul, obtained his Bachelor's degree in B.E Civil Engineering from PSNA College of Engineering and Technology (Dindigul), Anna University, Chennai, India. Currently he is pursuing, Master's degree in M.E Structural Engineering from PSNA College of Engineering and Technology (Dindigul), Anna University, Chennai, India. He has 1 year of Industrial experience. He has published1paper in International conferences. His area of interest is on Strength of materials, Design of Reinforced concrete structural elements.

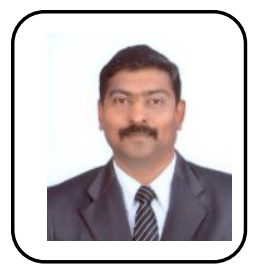

Dr. R.Vandhiyan obtained his Bachelor's degree in B.E Civil Engineering from Institute of Road and Transport Technology (Erode), Bharathiar University, Coimbatore, India. Then he obtained his Master's degree in M.E Structural Engineering from Mepco Schlenk Engineering College, (Virudhunagar), Anna University, Chennai, India. He was awarded Doctorate degree in Structural Engineering from Anna University, Chennai, India. He has 7.5 years of Industrial experience and 9 years of Teaching experience. Currently, working as an Assistant Professor in the Department of Civil Engineering, PSNA College of Engineering and Technology, Dindigul, Tamilnadu, India. He has guided many UG and PG projects. He extends his research knowledge by guiding many UG and PG projects. He has published many papers in International journals and conferences. He has wide experience in the reinforced concrete structures design. He has attended many conferences, workshops, seminars, Faculty Development and Training programs.

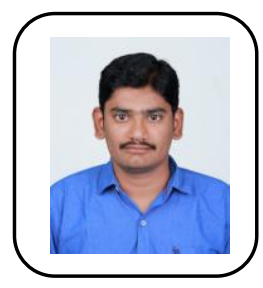

Mr.T.J. Vijay obtained his Bachelor's degree in Civil Engineering from Rajalakshmi Engineering College, Anna University, Chennai, India. He received his Master's Degree in Structural Engineering from PSNA College of Engineering and Technology (Dindigul), Anna University, Chennai, India. Currently working as an Assistant Professor in the Department of Civil Engineering, PSNA College of Engineering and Technology,

Dindigul, Tamilnadu, India. Presently he is pursuing Ph.D degree under Anna University, Chennai. His research interest is mainly on seismic performance of Concrete Structures. He has published over 3 technical papers.

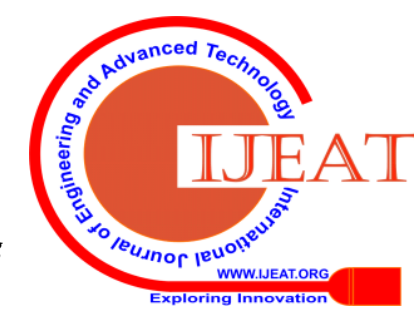

